\title{
Study on Radical Telomerization of Esters of Methacrylic Acid Using Bromotrichloromethane and Characteristics of the Resulting Telomers VI. ${ }^{\dagger}$ Difunctional Methacrylates
}

\author{
Takao KIMURA and Motome HAMASHIMA \\ Department of Environmental Chemistry, Faculty of Engineering, \\ Utsunomiya University, Ishii-cho, Utsunomiya 321, Japan
}

(Received June 12, 1987)

\begin{abstract}
The radical telomerization of vinyl (VMA) and allyl (AMA) methacrylates was carried out using bromotrichloromethane (BTCM) as a telogen at 50,70 , and $90^{\circ} \mathrm{C}$. The $m\left[\mathrm{Cl}_{3} \mathrm{CBr}\right]: n$ [Monomer]adducts $(m=1,2,3 ; n=1,2)$ were fractionated by means of silica gel column chromatography. Compared with VMA, AMA was subject to addition of BTCM and telomerized with a lower average degree of telomerization. The addition of BTCM occurred on both the vinylidene and vinyl groups, but the vinylidene group was much more susceptible to addition of BTCM in preference to the vinyl group. Furthermore, the chain of dimeric adducts was exclusively made up by a vinylidene-vinylidene coupling. The successive addition reaction of BTCM to telomeric molecules increased with temperature, time, and quantity of $2,2^{\prime}$-azobisisobutyronitrile (AIBN) as an initiator. In the telomerization at $90^{\circ} \mathrm{C}$, however, the addition rate of BTCM decreased in response to rapid inactivation of AIBN. The lactonization of dimeric adducts ( $m=1, n=2)$ was induced by the catalytic action of silica gel or heating. The lactone yield of the AMA adducts was higher than that of the VMA one. The VMA adduct was preferentially oligomerized by pyrolysis at $150^{\circ} \mathrm{C}$.

KEY WORDS Radical Telomerization / Difunctional Monomers / Vinyl Methacrylate / Allyl Methacrylate / Bromotrichloromethane / Telomerization Behavior / Structure of Adducts / Tacticity / Addition / Lactonization /
\end{abstract}

Bromotrichloromethane (BTCM) is known as an effective telogen for the radical telomerization of vinyl monomers by kinetic studies. ${ }^{1-5}$ However, there have been reported few studies on the telomerization behavior of vinyl monomers using BTCM as a telogen and characteristics of the resulting telomers.

In previous papers, ${ }^{6-10}$ we reported the radical telomerization of eleven kinds of monofunctional methacrylates using BTCM as a telogen. The effects of the substituent in the ester group on the telomerization behavior of these monomers and characteristics of the resulting telomers were systematically studied.
The telomerization behavior of alkyl methacrylates and reactivity of the resulting telomers were greatly dependent on the degree of branching rather than the length of the alkyl chain. In particular, $t$-butyl methacrylate showed its own characteristics in many respects. On the other hand, the telomerization behavior of aryl methacrylates, except for 9 fluorenyl methacrylate, resembled that of primary alkyl methacrylates in distribution of degree of telomerization (MWD) and tacticity. However, the apparent rate of telomerization of aryl methacrylates was lower than that of alkyl methacrylates in general. Furthermore,

\footnotetext{
+ Part $\mathrm{I}-\mathrm{V}$ of this series are ref $6-10$.
} 
the aromatic and aliphatic telomers differed remarkably from each other in reactivity.

As a part of the study program, this work deals with the radical telomerization of difunctional monomers, that is, vinyl (VMA) and allyl (AMA) methacrylates using BTCM. Since these methacrylates have a labile vinyl substituent in the ester group besides a existing vinylidene substituent, interesting telomerization behavior can be expected. Furthermore, the resulting telomers are favorable for the transformation into more useful oligomers because they contain more halogen groups. In this paper, the effects of temperature, time, quantity of 2,2'-azobisisobutyronitrile (AIBN) as an initiator and its addition method on the telomerization behavior are described in detail, and the differences in reactivity between VMA and AMA are discussed.

\section{EXPERIMENTAL}

\section{Measurements}

The same instruments and methods as described previously ${ }^{7}$ were used in this study.

\section{Telomerization Procedure}

Telomerization was carried out at 50, 70, and $90^{\circ} \mathrm{C}$ for prescribed hours in the presence of a desired amount of AIBN under the conditions of $\left[\mathrm{Cl}_{3} \mathrm{CBr}\right]_{0} /[\text { Monomer }]_{0}=20$. The reaction mixture was treated by a similar manner as described in the previous paper. $^{6}$ Commercial VMA and AMA were purified by a conventional method. Commercial BTCM was purified by distillation under reduced pressure, and AIBN by recrystallization from methanol.

\section{Fractionation of Adducts}

The adducts were fractionated by means of column chromatography using silica gel (Wakogel C-300) as packing material. The monomeric adducts $(n=1)$ were developed with carbon tetrachloride as the eluent, and their eluting order was as follows: 2:1-
$\left[\mathrm{Cl}_{3} \mathrm{CBr}\right]$ : [Monomer]adduct (M-2) $>1: 1$-adduct (M-1). Strongly adsorbed dimeric adducts $(n=2)$ were developed with $2: 2: 1$ cyclohexane: carbon tetrachloride: benzene for VMA telomers, 2:1-carbon tetrachloride : benzene for AMA telomers as the eluent, and their eluting order was as follows: 3:2$\left[\mathrm{Cl}_{3} \mathrm{CBr}\right]:$ [Monomer]adduct (D-3) $\geqq 2: 2$-adduct (D-2) $>1: 2$-adduct (D-1). When necessary, the fraction containing D-1 was further developed with $1: 1$-cyclohexane: benzene as the eluent, and two diastereoisomers were eluted in the following order: syndiotactic type (D-1a) $>$ isotactic type (D-1b). More strongly adsorbed components containing lactones and oligomers higher than the dimer were desorbed with methanol.

\section{Reactions of Adducts}

Addition Reaction with BTCM. To a solution of an adduct $\left(7.30 \times 10^{-4} \mathrm{~mol}\right)$ in benzene, a desired amount of BTCM was added. The mixture was refluxed for $4 \mathrm{~h}$ in the presence of AIBN $\left(1.20 \times 10^{-4} \mathrm{~mol}\right)$. The reaction mixture was treated in a manner similar to that in the foregoing telomerization.

Catalytic Reaction with Silica Gel. To a solution of D-1 ( $0.3 \mathrm{~g}$ in $9 \mathrm{ml}$ dry benzene), $3 \mathrm{~g}$ of silica gel (Wakogel C-300 dried at 180 $200^{\circ} \mathrm{C}$ for $3 \mathrm{~h}$ ) were added, and the suspended mixture was stirred at the required temperature for prescribed hours. The reaction mixture was treated by the same method as described in the previous paper. ${ }^{7}$ The resulting lactone was separated by means of silica gel column chromatography with benzene as the eluent, and when necessary, carboxylic acid DLc, mp $177-179^{\circ} \mathrm{C}(\mathrm{dec}){ }^{7}$ was separated by extraction with $3 \%$ aqueous sodium hydroxide.

Pyrolysis. The dimeric adduct D-1 was directly heated at $150^{\circ} \mathrm{C}$ for $2 \mathrm{~h}$. The product was separated in the same way as above. 
Telomerization of Difunctional Monomers with $\mathrm{Cl}_{3} \mathrm{CBr}$

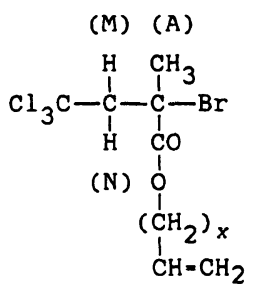

M-1a
(A)

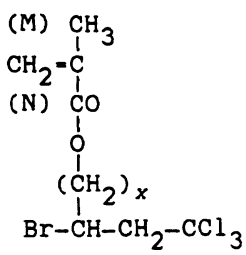

M-1b<smiles>CC(C)(Cl)CC(Br)COC(=O)C(C)(Br)C(C)(Cl)Cl</smiles>

M-2<smiles>[Y]C(C)COC(=O)C(C)(Br)C(C)C(C)(C(=O)OCCCC)C(C)C</smiles>

D-1a

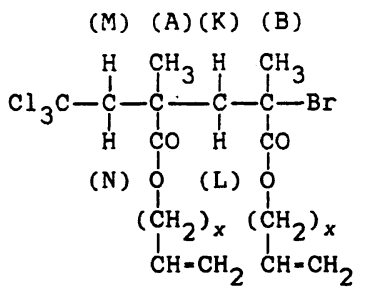

D-1b
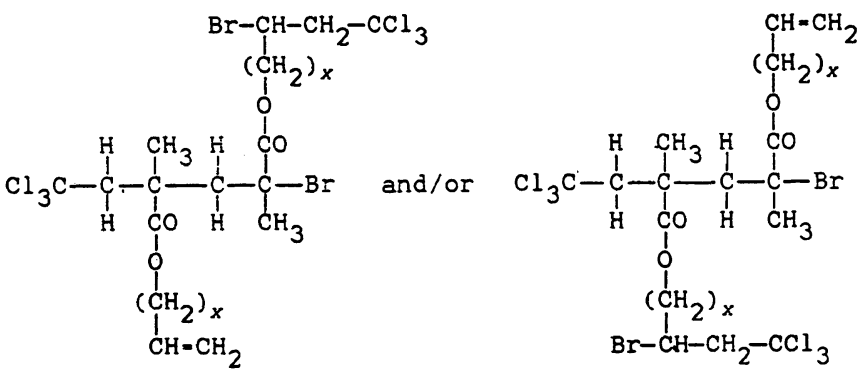

D-2a
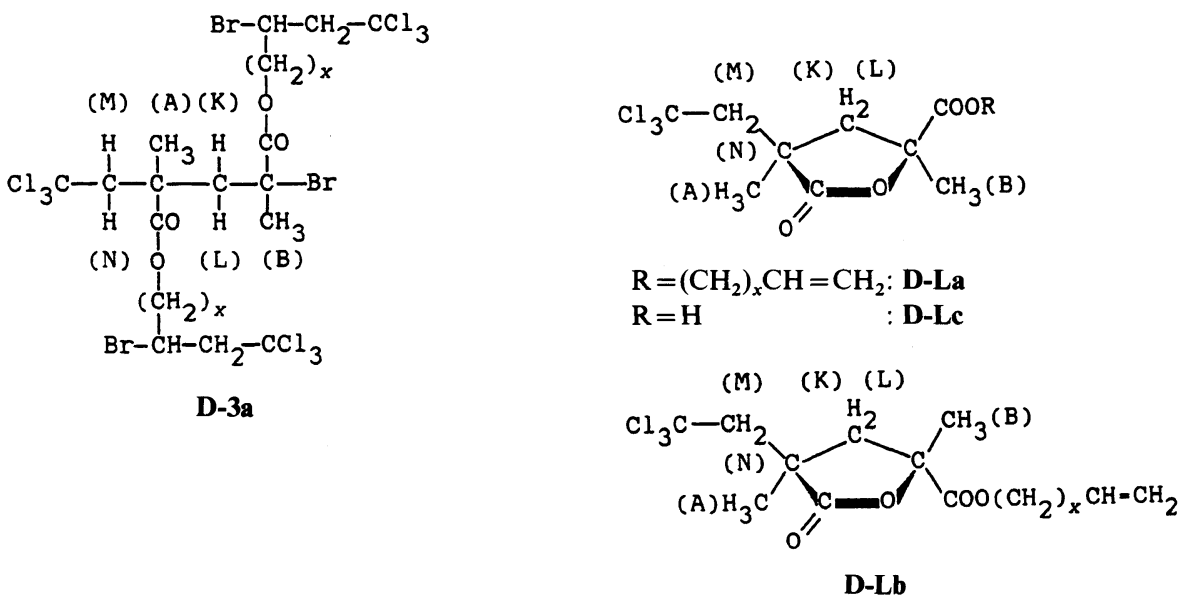


\section{RESULTS AND DISCUSSION}

\section{Telomerization of Difunctional Methacrylates with BTCM}

The results of the radical telomerization of VMA and AMA with BTCM are summarized in Tables I, II, III, and Figures 1, 2. The MWD was greatly dependent on temperature rather than time and quantity of AIBN as shown in Tables I and II. The MWD of AMA was analogous to that of primary alkyl methacrylates $^{7}$ with formation of lactones, while the MWD of VMA shifted to a higher degree of telomerization without formation of lactones. In the telomerization of AMA, lactones were remarkably formed at the lowest AIBN concentration as shown in Table II. As the reaction temperature, time, and quantity of AIBN increased as shown in Figures 1, 2, and Table II, the successive addition reaction of BTCM in $n$-mers $(n=1,2)$ proceeded by the following routes: $\mathbf{M}-\mathbf{1} \rightarrow \mathbf{M}-\mathbf{2} ; \mathbf{D}-\mathbf{1} \rightarrow \mathbf{D}-\mathbf{2} \rightarrow \mathbf{D}-\mathbf{3}$. The addition rate of BTCM of AMA was higher than that of VMA. In the telomerization of both monomers at $90^{\circ} \mathrm{C}$, however, the addition reaction of BTCM proceeded very slowly in spite of lapse of time. On the other hand, as can be seen from Table III, the MWD of VMA was independent of the addition method of AIBN, but the successive addition reaction of BTCM in $n$-mers $(n=1,2)$ proceeded until the final adducts, namely M-2 and D-3 were produced thoroughly; by adding equivalent AIBN in two times. Similar behavior was also observed in the telomerization of AMA.

\section{Addition Behavior of BTCM in n-mers}

1-mer. The addition of BTCM to VMA and AMA occurred on both the vinylidene and vinyl groups, but the vinylidene group was much more susceptible to the addition of BTCM in comparison with the vinyl group. Therefore, adduct M-1a was formed much more than M-1b. The formation of $\mathbf{M}-\mathbf{1 b}$ was detected in a small proportion when AMA was
Table I. Effects of temperature and time on the telomerization behavior of vinyl and allyl methacrylates ${ }^{\mathrm{a}}$

\begin{tabular}{|c|c|c|c|c|c|c|}
\hline \multirow{2}{*}{ Monomer } & \multirow{2}{*}{$\frac{\text { Temp }}{{ }^{\circ} \mathrm{C}}$} & \multirow{2}{*}{$\frac{\text { Time }}{\mathrm{h}}$} & \multirow{2}{*}{$\frac{\text { Yield }^{\mathrm{b}}}{\%}$} & \multicolumn{3}{|c|}{ MWD $/ w t \%$} \\
\hline & & & & $n=1$ & $n=2^{\mathrm{c}}$ & $n \geqq 3$ \\
\hline \multirow{10}{*}{ VMA } & \multirow{2}{*}{50} & 16 & 148 & 8 & $10[0]$ & 82 \\
\hline & & 48 & 261 & 12 & $10[0]$ & 78 \\
\hline & \multirow{4}{*}{70} & 2 & 145 & 12 & $14[0]$ & 74 \\
\hline & & 4 & 205 & 13 & $12[0]$ & 75 \\
\hline & & 8 & 336 & 19 & $15[0]$ & 66 \\
\hline & & 16 & 361 & 19 & $18[0]$ & 63 \\
\hline & \multirow{4}{*}{90} & 2 & 270 & 32 & $17[0]$ & 51 \\
\hline & & 4 & 290 & 26 & $15[0]$ & 59 \\
\hline & & 8 & 291 & 28 & $18[0]$ & 54 \\
\hline & & 16 & 309 & 24 & $15[0]$ & 61 \\
\hline \multirow{10}{*}{ AMA } & \multirow{2}{*}{50} & 16 & 84 & 21 & $24[3]$ & 55 \\
\hline & & 48 & 370 & 28 & $22[0]$ & 50 \\
\hline & \multirow{4}{*}{70} & 2 & 166 & 33 & 30 [3] & 37 \\
\hline & & 4 & 278 & 36 & 27 [2] & 37 \\
\hline & & 8 & 364 & 36 & $28[2]$ & 36 \\
\hline & & 16 & 371 & 35 & 30 [2] & 35 \\
\hline & \multirow{4}{*}{90} & 2 & 290 & 44 & $28[1]$ & 28 \\
\hline & & 4 & 298 & 43 & $27[2]$ & 30 \\
\hline & & 8 & 304 & 43 & $25[3]$ & 32 \\
\hline & & 16 & 327 & 43 & $27[4]$ & 30 \\
\hline
\end{tabular}

a $[\text { Monomer }]_{0}, 4.70 \times 10^{-2} \mathrm{~mol} ;[\mathrm{BTCM}]_{0}, 9.40 \times 10^{-1}$ mol; $[\mathrm{AIBN}]_{0}, 2.22 \times 10^{-3} \mathrm{~mol}$.

b $[$ Total amount of product $(\mathrm{g}) /$ Monomer $(\mathrm{g})] \times 100$.

c [ ], content of dimeric lactones.

telomerized at the lowest AIBN concentration, as shown in Table II. Table IV shows the results of the addition reaction of the initial adducts with BTCM. The initial adduct M-1a gave M-2 quantitatively with the addition of BTCM. Hence, adduct M-2 proved to be exclusively formed by way of M-1a in the telomerization.

Dimer. The chain of dimeric adducts was exclusively made up by vinylidene-vinylidene coupling. There were two dimeric diastereoisomers, D-1a and D-1b, as initial adducts in the ratio shown in Table $\mathrm{V}$. The telomerization behavior of VMA and AMA had great 

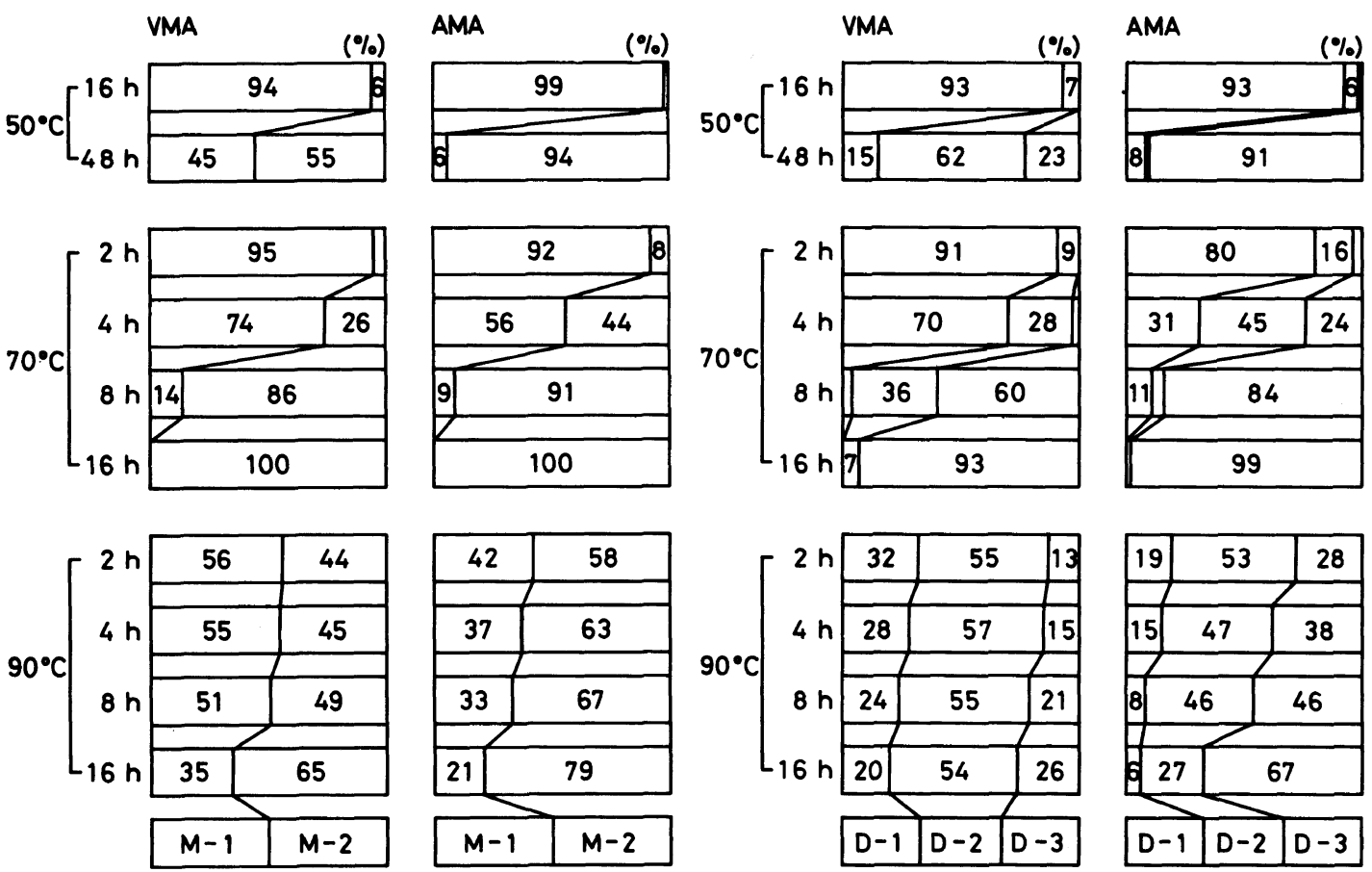

Figure 1. Distribution ratio of adducts in 1-mer obtained under the conditions in Table $\mathbf{I}$.

Figure 2. Distribution ratio of adducts in dimer obtained under the conditions in Table I.

Table II. Effects of quantity of AIBN on the telomerization behavior of vinyl and allyl methacrylates ${ }^{a}$

\begin{tabular}{|c|c|c|c|c|c|c|c|c|c|c|}
\hline \multirow{2}{*}{ Monomer } & \multirow{2}{*}{$\frac{[\mathrm{AIBN}]_{0} \times 10^{3}}{\mathrm{~mol}}$} & \multirow{2}{*}{$\frac{\text { Yield }^{\mathrm{b}}}{\%}$} & \multicolumn{3}{|c|}{ MWD $/ w t^{\circ} \%$} & \multicolumn{2}{|c|}{$1-\operatorname{mer} / \%$} & \multicolumn{3}{|c|}{ Dimer $/ \%$} \\
\hline & & & $n=1$ & $n=2^{\mathrm{b}}$ & $n \geqq 3$ & M-1 & M-2 & D-1 & D-2 & D-3 \\
\hline \multirow{3}{*}{ VMA } & 0.14 & 116 & 13 & $12[0]$ & 75 & 96 & 4 & 94 & 6 & 0 \\
\hline & 0.55 & 198 & 13 & $14[0]$ & 73 & 78 & 22 & 75 & 23 & 2 \\
\hline & 2.22 & 336 & 19 & $15[0]$ & 66 & 14 & 86 & 4 & 36 & 60 \\
\hline \multirow{3}{*}{ AMA } & 0.14 & 136 & 44 & 29 [11] & 27 & $94^{\mathrm{c}}$ & 6 & 83 & 17 & 0 \\
\hline & 0.55 & 226 & 38 & $33[2]$ & 29 & 82 & 18 & 52 & 39 & 9 \\
\hline & 2.22 & 364 & 36 & 28 [ 2] & 36 & 9 & 91 & 11 & 5 & 84 \\
\hline
\end{tabular}

a $[\text { Monomer }]_{0}, 4.70 \times 10^{-2} \mathrm{~mol} ;[\mathrm{BTCM}]_{0}, 9.40 \times 10^{-1} \mathrm{~mol}$; temp, $70^{\circ} \mathrm{C}$; time, $8 \mathrm{~h}$.

b See Table I.

c $\mathbf{M - 1 a}: \mathbf{M - 1 b}=97: 3$.

resemblance to that of conventional monofunctional methacrylates in tacticity. On the other hand, since a mixture of dimeric adducts D-2 and D-3 was inseparable by means of column chromatography with silica gel, it was impossible to determine their addition structure and tacticity. However, dimeric adduct D-1a proved to be successively converted to D-2a and D-3a by a series of addition reactions of BTCM shown in Table IV. 
Table III. Effect of the addition method of AIBN on the telomerization behavior of vinyl methacrylate ${ }^{\mathrm{a}}$

\begin{tabular}{|c|c|c|c|c|c|c|c|c|c|c|}
\hline \multicolumn{2}{|c|}{$[\mathrm{AIBN}]_{0} \times 10^{3} / \mathrm{mol}$} & \multirow{2}{*}{$\frac{\text { Yield }^{\mathbf{b}}}{\%}$} & \multicolumn{3}{|c|}{$\mathrm{MWD} / \mathrm{wt} \%$} & \multicolumn{2}{|c|}{$1-\operatorname{mer} / \%$} & \multicolumn{3}{|c|}{ Dimer $/ \%$} \\
\hline Start & After $2 \mathrm{~h}$ & & $n=1$ & $n=2$ & $n \geqq 3$ & M-1 & M-2 & D-1 & D-2 & D-3 \\
\hline 2.22 & - & 290 & 26 & 15 & 59 & 55 & 45 & 28 & 57 & 15 \\
\hline 1.11 & 1.11 & 391 & 25 & 18 & 57 & 0 & 100 & 0 & 5 & 95 \\
\hline
\end{tabular}

${ }^{\mathrm{a}}[\mathrm{VMA}]_{0}, 4.70 \times 10^{-2} \mathrm{~mol} ;[\mathrm{BTCM}]_{0}, 9.40 \times 10^{-1} \mathrm{~mol}$; temp, $90^{\circ} \mathrm{C}$; time, $4 \mathrm{~h}$.

b See Table I.

Table IV. Reactions of initial adducts with $\mathrm{Cl}_{3} \mathrm{CBr}$

\begin{tabular}{|c|c|c|c|c|c|c|c|}
\hline \multirow{2}{*}{ Adduct } & \multirow{2}{*}{$X$} & \multirow{2}{*}{$\frac{\left[\mathrm{Cl}_{3} \mathrm{CBr}\right]}{\text { [Adduct }]}$} & \multirow{2}{*}{$\frac{\mathrm{C}_{6} \mathrm{H}_{6}}{\mathrm{ml}}$} & \multicolumn{3}{|c|}{ Products $/ \%$} & \multirow{2}{*}{$\frac{\text { Recovd. }}{\%}$} \\
\hline & & & & M-2 & D-2a & D-3a & \\
\hline \multirow{2}{*}{ M-1a } & 0 & 100 & 0 & 100 & & & - \\
\hline & 1 & 100 & 0 & 100 & & & - \\
\hline \multirow{4}{*}{ D-1a } & 0 & 2 & 10 & & 41 & 3 & 56 \\
\hline & 1 & 2 & 10 & & 48 & 23 & 29 \\
\hline & 0 & 100 & 0 & & 一 & 100 & - \\
\hline & 1 & 100 & 0 & & - & 100 & - \\
\hline
\end{tabular}

Table V. Tacticity of $1: 2-\left[\mathrm{Cl}_{3} \mathrm{CBr}\right]:$ [Monomer]adducts obtained in the radical telomerization ${ }^{\mathrm{a}}$

\begin{tabular}{|c|c|c|c|c|}
\hline \multirow{2}{*}{ Monomer } & \multirow{2}{*}{$\frac{\text { Temp }}{{ }^{\circ} \mathrm{C}}$} & \multirow{2}{*}{$\frac{\text { Time }}{\mathrm{h}}$} & \multicolumn{2}{|c|}{ Tacticity $/ \%$} \\
\hline & & & D-1a & D-1b \\
\hline \multirow{3}{*}{ VMA } & 50 & 16 & 81 & 19 \\
\hline & 70 & 2 & 76 & 24 \\
\hline & 90 & 2 & 68 & 32 \\
\hline \multirow{3}{*}{ AMA } & 50 & 16 & 90 & 10 \\
\hline & 70 & 2 & 87 & 13 \\
\hline & 90 & 2 & 85 & 15 \\
\hline
\end{tabular}

a See Table I.

\section{Consideration on Anomalous Addition Behavior at $90^{\circ} \mathrm{C}$}

Figure 3 shows the time-conversion plots of the addition of BTCM to M-1a $(x=0)$. The addition rate increased with reaction temperature. Therefore, the addition behavior of BTCM at $90^{\circ} \mathrm{C}$ shown in Figures 1 and 2 evidently conflicts with this behavior. That is

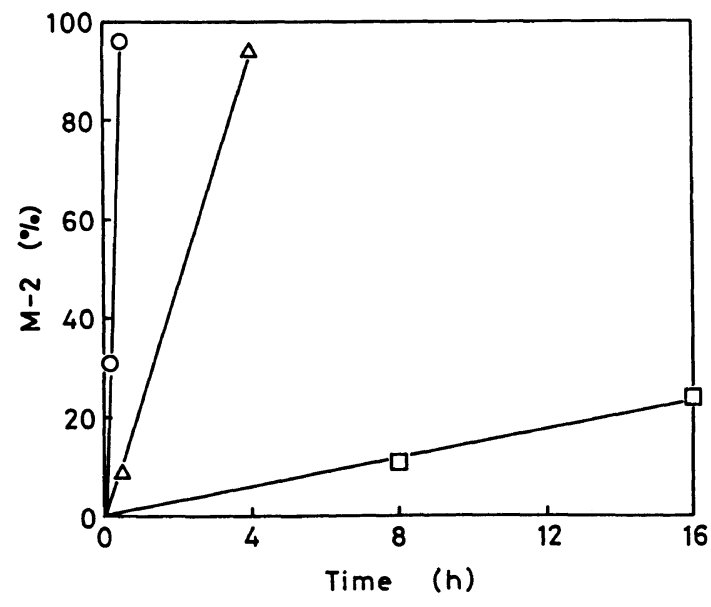

Figure 3. Time-conversion plots of addition of $\mathrm{Cl}_{3} \mathrm{CBr}$ to 1 : 1-adduct: $[\mathrm{M}-1 \mathrm{a}(x=0)]_{0}, 9.67 \times 10^{-4} \mathrm{~mol}$; $\left[\mathrm{Cl}_{3} \mathrm{CBr}\right]_{0}, 1.94 \times 10^{-2} \mathrm{~mol} ;[\mathrm{AIBN}]_{0}, 9.36 \times 10^{-5} \mathrm{~mol}$; $\square, 50^{\circ} \mathrm{C} ; \triangle, 70^{\circ} \mathrm{C} ; \mathrm{O}, 90^{\circ} \mathrm{C}$.

to say, although the addition rate of BTCM at $90^{\circ} \mathrm{C}$ ought to be essentially higher than that at $70^{\circ} \mathrm{C}$, the addition rate of $\mathrm{BTCM}$ at $70^{\circ} \mathrm{C}$ appears to be higher than that at $90^{\circ} \mathrm{C}$ in the actual telomerization. It is thought that AIBN is liable to inactivation in the telomerization at $90^{\circ} \mathrm{C}$ nearest the decomposition point $\left(106^{\circ} \mathrm{C}\right)$, and that its activity becomes poor for the successive addition of BTCM. This consideration is satisfactorily supported by the results shown in Table III.

\section{Identification of Adducts}

The homologous adducts are characterized as shown in Table VI. The IR absorption maxima of $\mathrm{C}=\mathrm{O}$ stretching vibration of the 
Telomerization of Difunctional Monomers with $\mathrm{Cl}_{3} \mathrm{CBr}$

Table VI. Characterization of fractionated adducts

\begin{tabular}{|c|c|c|c|c|c|c|}
\hline \multirow{2}{*}{ Adduct } & \multirow{2}{*}{$X$} & \multirow{2}{*}{ Shape ${ }^{a}$} & \multirow{2}{*}{$\frac{\mathrm{mp}[\mathrm{bp}]}{{ }^{\circ} \mathrm{C}}$} & \multirow{2}{*}{$\frac{v(\mathrm{C}=\mathrm{O})}{\mathrm{cm}^{-1}}$} & \multirow{2}{*}{$\frac{v(\mathrm{C}=\mathrm{C})}{\mathrm{cm}^{-1}}$} & \multirow{2}{*}{$m / z\left(\mathrm{QM}^{+}\right)$} \\
\hline & & & & & & \\
\hline \multirow{2}{*}{ M-1a } & 0 & $\mathrm{C}$ & [ $92 / 6 \mathrm{mmHg}]$ & 1760 & 1650 & 309 \\
\hline & 1 & $\mathrm{C}$ & {$[104 / 2 \mathrm{mmHg}]$} & 1750 & 1650 & 323 \\
\hline M-1b & 1 & $\mathrm{C}$ & - & 1735 & 1640 & 323 \\
\hline \multirow{2}{*}{ M-2 } & 0 & A & $46.0-48.5$ & 1770 & & 505 \\
\hline & 1 & B & - & 1745 & & 519 \\
\hline \multirow{2}{*}{ D-1a } & 0 & B & - & 1760 & 1650 & 421 \\
\hline & 1 & A & $48.5-50.0$ & 1740 & 1640 & 449 \\
\hline \multirow{2}{*}{ D-1b } & 0 & B & - & 1750 & 1645 & 421 \\
\hline & 1 & B & - & 1740 & 1645 & 449 \\
\hline \multirow{2}{*}{ D-3a } & 0 & A & $111.0-114.0$ & 1770 & & $-^{\mathrm{b}}$ \\
\hline & 1 & B & - & 1745 & & $-^{\mathrm{b}}$ \\
\hline \multirow{2}{*}{ D-La } & 0 & A & $76.5-79.0$ & 1780,1750 & 1645 & 315 \\
\hline & 1 & A & $54.5-57.0$ & 1775,1760 & 1650 & 329 \\
\hline D-Lb & 1 & B & - & 1780,1750 & 1650 & 329 \\
\hline
\end{tabular}

a A, colorless crystals; B, colorless viscous oil; C, colorless liquid.

b Not measured.

VMA homologues in general appeared at a higher wavenumber relative to that of the AMA ones. Identical fragmentation ion peaks were detected in the mass spectra of the homologues. That is, the $\alpha$-cleavage of ester groups and cleavage between bromine and carbon atoms occurred preferentially.

The ${ }^{1} \mathrm{H}$ NMR parameters of the homologues are listed in Table VII. The same symbolized methyl- and methylene-proton signals of the VMA homologues resonated somewhat in lower magnetic fields relative to those of the AMA homologues. This shift may be interpreted by a difference in electron-attractive force between the vinyl- and allyl-ester groups. The proton signals of the ester groups, which are omitted in the table, appeared in the expected resonance regions.

\section{Reactivity of Telomers}

Catalytic Reaction with Silica Gel. The lactonization of D-1 was induced by the catalytic action of silica gel. As shown in Table VIII, this reaction selectively proceeded by the following routes: D-1a $\rightarrow$ D-La and D-1b $\rightarrow$ D-Lb. The conversion yields of D-1a $(x=1)$ and D-1b $(x=1)$ were analogours to those of the corresponding dimeric methyl methacrylate telomers ${ }^{7}$ under similar conditions. On the other hand, the lactonization of D-1a $(x=0)$ at $30^{\circ} \mathrm{C}$ resulted in a lowering of the conversion yield, and the resulting lactone D-La $(x=0)$ was further transformed to D-Lc with an increase in reaction temperature. The complete conversion of D-La $(x=1)$ into D-Lc was not observed in the reaction of AMA at $50^{\circ} \mathrm{C}$. Thus, the vinyl ester group directly bonded to a lactone ring was found to be subject to carboxylation by the catalytic action of silica 
Table VII. ${ }^{1} \mathrm{H}$ NMR parameters of fractionated adducts in $\mathrm{CCl}_{4}$

\begin{tabular}{|c|c|c|c|c|}
\hline \multirow{2}{*}{ Adduct } & \multirow{2}{*}{ Proton } & \multirow{2}{*}{ Symbol } & \multicolumn{2}{|c|}{ Chemical shift $\delta / \mathrm{ppm}$} \\
\hline & & & VMA & AMA \\
\hline M-1a & $\begin{array}{l}-\mathrm{CH}_{3} \\
-\mathrm{CH}_{2-}^{-}\end{array}$ & $\stackrel{\mathrm{A}}{\mathrm{M}, \mathrm{N}}$ & $\begin{array}{c}2.28 \\
4.323 .59 \\
(15.6)^{\mathrm{a}}\end{array}$ & $\begin{array}{c}2.20 \\
4.273 .52 \\
(15.6)\end{array}$ \\
\hline M-1b & $\begin{array}{l}-\mathrm{CH}_{3} \\
=\mathrm{CH}_{2}\end{array}$ & $\stackrel{\mathrm{A}}{\mathrm{M}, \mathrm{N}}$ & & $\begin{array}{c}1.94 \\
6.085 .55\end{array}$ \\
\hline M-2 & $\begin{array}{l}-\mathrm{CH}_{3} \\
-\mathrm{CH}_{2}-\end{array}$ & $\begin{array}{c}\mathrm{A} \\
\mathrm{M}, \mathrm{N}\end{array}$ & $\begin{array}{c}2.25 \\
4.233 .53 \\
(15.0)\end{array}$ & $\begin{array}{cl} & 2.25 \\
4.31 & 3.56 \\
(15.0)\end{array}$ \\
\hline D-1a & $\begin{array}{l}-\mathrm{CH}_{3} \\
-\mathrm{CH}_{3} \\
-\mathrm{CH}_{2}- \\
-\mathrm{CH}_{2}-\end{array}$ & $\begin{array}{c}\text { A } \\
\text { B } \\
\text { K, L } \\
\text { M, N }\end{array}$ & $\begin{array}{c}1.90 \\
1.38 \\
2.91 \\
3.592 .94 \\
(15.6)\end{array}$ & $\begin{array}{c}1.88 \\
1.33 \\
2.972 .70 \\
(14.4) \\
3.592 .88 \\
(15.0)\end{array}$ \\
\hline D-1b & $\begin{array}{l}-\mathrm{CH}_{3} \\
-\mathrm{CH}_{3} \\
-\mathrm{CH}_{2-} \\
-\mathrm{CH}_{2-}\end{array}$ & $\begin{array}{c}\text { A } \\
\text { B } \\
\mathbf{K}, \mathrm{L} \\
\mathbf{M}, \mathbf{N}\end{array}$ & $\begin{array}{c}2.03 \\
1.64 \\
2.962 .52 \\
(15.0) \\
3.652 .99 \\
(15.6)\end{array}$ & $\begin{array}{c}1.99 \\
1.58 \\
2.902 .43 \\
(15.0) \\
3.642 .93 \\
(15.0)\end{array}$ \\
\hline D-3a & $\begin{array}{l}-\mathrm{CH}_{3} \\
-\mathrm{CH}_{3} \\
-\mathrm{CH}_{2}- \\
-\mathrm{CH}_{2}-\end{array}$ & $\begin{array}{c}\text { A } \\
\text { B } \\
\mathrm{K}, \mathrm{L} \\
\mathrm{M}, \mathrm{N}\end{array}$ & $\begin{array}{c}2.03 \\
1.43 \\
3.102 .78 \\
(15.0) \\
3.633 .02 \\
(15.6)\end{array}$ & $\begin{array}{c}1.95 \\
1.42 \\
2.82 \\
3.592 .87 \\
(15.0)\end{array}$ \\
\hline D-La & $\begin{array}{l}-\mathrm{CH}_{3} \\
-\mathrm{CH}_{3} \\
-\mathrm{CH}_{2}- \\
-\mathrm{CH}_{2}-\end{array}$ & $\begin{array}{c}\text { A } \\
\text { B } \\
\mathrm{K}, \mathrm{L} \\
\mathrm{M}, \mathrm{N}\end{array}$ & $\begin{array}{c}1.74 \\
1.34 \\
2.82 \\
3.423 .09 \\
(15.6)\end{array}$ & $\begin{aligned} 1.67 \\
1.30 \\
2.74 \\
3.363 .05 \\
(15.6)\end{aligned}$ \\
\hline D-Lb & $\begin{array}{l}-\mathrm{CH}_{3} \\
-\mathrm{CH}_{3} \\
-\mathrm{CH}_{2}- \\
-\mathrm{CH}_{2}-\end{array}$ & $\begin{array}{c}\text { A } \\
\text { B } \\
\mathrm{K}, \mathrm{L} \\
\mathrm{M}, \mathrm{N}\end{array}$ & & $\begin{array}{c}1.67 \\
1.54 \\
3.292 .07 \\
(15.0) \\
3.18\end{array}$ \\
\hline
\end{tabular}

a ( ), coupling const $J$ in $\mathrm{Hz}$.

gel.

Pyrolysis. Table IX shows the results of the pyrolysis of D-1 in the absence of solvent.
Table VIII. Catalytic reactions of $1: 2-\left[\mathrm{Cl}_{3} \mathrm{CBr}\right]$ : [Monomer]adducts with silica gel

\begin{tabular}{|c|c|c|c|c|c|c|c|}
\hline \multirow{2}{*}{ Adduct } & \multirow{2}{*}{$X$} & \multirow{2}{*}{$\frac{\text { Temp }}{{ }^{\circ} \mathrm{C}}$} & \multirow{2}{*}{$\frac{\text { Time }}{h}$} & \multicolumn{4}{|c|}{ Yield of products $/ \%$ Recovd } \\
\hline & & & & D-La & D-Lb & D-Lc & $\%$ \\
\hline \multirow{5}{*}{ D-1a } & & 30 & & 13 & - & - & 87 \\
\hline & 0 & 40 & 72 & 30 & - & 27 & 43 \\
\hline & & 50 & & - & - & 80 & - \\
\hline & 1 & 30 & 72 & 76 & - & - & 24 \\
\hline & 1 & 50 & & 100 & - & - & - \\
\hline D-1b & 1 & 30 & 4 & - & 37 & - & 63 \\
\hline
\end{tabular}

Table IX. Pyrolysis of $1: 2-\left[\mathrm{Cl}_{3} \mathrm{CBr}\right]$ : [Monomer]adducts

\begin{tabular}{|c|c|c|c|c|c|}
\hline \multirow{2}{*}{ Adduct } & \multirow{2}{*}{$X$} & \multicolumn{3}{|c|}{ Yields of products $/ \%$} & \multirow{2}{*}{$\frac{\text { Recovd. }}{\%}$} \\
\hline & & D-La & D-Lb & Others & \\
\hline \multirow{2}{*}{ D-1a } & 0 & - & - & Oligomer & 19 \\
\hline & 1 & 86 & - & - & - \\
\hline D-1b & 1 & - & 95 & - & - \\
\hline
\end{tabular}

Heating of D-1a $(x=1)$ and D-1b $(x=1)$ at $150^{\circ} \mathrm{C}$ exclusively gave the corresponding lactones by the same routes as the catalytic lactonization with silica gel. On the other hand, heating of D-1a $(x=0)$ at $150^{\circ} \mathrm{C}$ resulted in oligomerization rather than lactonization. The vinyl ester group existing as a side-chain is considered responsible for the thermal oligomerization.

Acknowledgments. The authors are grateful to Miss F. Takano, Miss K. Fujino, Mr. T. Abiko, Mr. I. Kuroyanagi, and Mr. $\mathrm{H}$. Takiguchi for their help in this study.

\section{REFERENCES}

1. C. A. Barson, R. R. Mather, and J. C. Robb, Trans. Faraday Soc, 66, 2585 (1970).

2. D. A. J. Harker, R. A. M. Thomson, and I. R. Walters, Trans. Faraday Soc., 67, 3057 (1971).

3. C. A. Barson, A. R. Luxton, and J. C. Robb, J. Chem. Soc., Faraday Trans. 1, 68, 1666 (1972). 


\section{Telomerization of Difunctional Monomers with $\mathrm{Cl}_{3} \mathrm{CBr}$}

4. C. A. Barson, R. A. Batten, and J. C. Robb, Eur. Polym. J., 10, 97 (1974).

5. C. A. Barson and R. Ensor, Eur. Polym. J., 13, 53 (1977).

6. T. Kimura, T. Kodaira, and M. Hamashima, Polym. J., 15, 293 (1983).

7. T. Kimura and M. Hamashima, Polym. J., 18, 21
(1986).

8. T. Kimura, I. Nakanishi, and M. Hamashima, Polym. J., 18, 689 (1986).

9. T. Kimura, H. Tasaka, and M. Hamashima, Polym. J., 19, 305 (1987).

10. T. Kimura, T. Yoshimura, H. Morimoto, and $\mathbf{M}$. Hamashima, Polym. J., 19, 1165 (1987). 